\title{
How Do Enterprise Software Providers Adapt Their Strategies to the Cloud? An Analysis through SAP Hana Journey Based on the Evolution of SAP's Discourse (2010-2018)
}

\author{
Lise Arena \\ UCA, CNRS, GREDEG, France \\ lise.arena@univ-cotedazur.fr \\ Nicolas Remond \\ UCA, CNRS, GREDEG, France \\ nicolas.remond@etu.univ-cotedazur.fr
}

\begin{abstract}
This paper seeks to provide a better understanding of software business providers' strategy when adapting to the emergence of cloud computing markets. Based on a longitudinal case-study and on a historical content analysis of SAP's discourse, it highlights four main periods of adaptation, since 2009. The analysis of these four periods emphasizes the existence of an initial superior technology (HANA) on the ERP market when referring to cloud-based solutions. Overall, the evolution of SAP's strategy is understood as a change from a high level of control over the administration of its technological environment to a more flexible strategy that gives alternative options such as Platform-as-aService (PaaS) and Infrastructure-as-a-Service (IaaS) mode. Content analysis shows that SAP's discourse gives an increasing importance to agreements with third parties in order to mitigate the perception of the perceived lock-in effect.
\end{abstract}

\section{Introduction}

The evolution of ERP (Enterprise Resource Planning) systems and, more generally, of the enterprise software industry has been largely discussed by historians of computing [2, 9] and scholars in management of information systems [27, 4]. Overall, the enterprise software industry developed at the same time as firms moved from in-house designed information systems to modular, scalable and tailormade integrated systems. This increasing complexity of organizational structures and information flows continuously offered new challenges to ERP vendors, who aligned their strategies with the emergence of platform economies and their ecosystems [15].

\author{
Lapo Mola \\ UCA, CNRS, GREDEG, SKEMA, France \\ lapo.mola@skema.edu
}

Frantz Rowe

LEMNA, IAE de Nantes, Nantes University and KTO, SKEMA Business School, France Frantz.Rowe@univ-nantes.fr
The transformation of ERP vendors from software providers to platform's governors has deep business and strategic implication [8]. Platforms are not purely modular systems; as the level of interaction, interdependency and imbrication of the different platform's components produces lock-in effect that is worth being investigated further $[8,25,28]$. While cloud-based applications' opportunities are increasingly discussed in the literature; challenges are less known so far as the few existing publications focus on privacy policies' reception and confidentiality concerns [14]. Yet, early results consider switching costs, legal restrictions and organizational change as the main challenges in the adoption of cloud-based enterprise systems [26].

In a world where collaborative standards development process enables downstream innovation, new forms of value capture impacts the profiting from innovation [32]. To a large extent, this shift in platform boundaries and these new sources of profit addressed new questions to software providers who faced the choice: proprietorship and customization versus more open architectures to capture value. This choice cannot be understood in isolation from the evolution of global organization of digital innovation and the emergence of disruptive technologies. The development of cloud computing reflects this tendency as it has two main functionalities: flexibility of computing architecture and more collaborative business. Put differently, it has the potential to radically change the ERP environment; shifting from data housed on-premise to data hosted by vendors who provide real-time access to the application. As a result of these recent changes, cloud computing is meant to reach a degree of platform openness enabling platform boundary resources to support complements.

Up to recently [30], IS research has been of limited help to understand vendors or partners' challenges and 
coping strategies with the shift to the cloud. Yet, paradoxically, as soon as 2014, bibliographic studies of ERP research had shown that this issue, identified as a gap, had to be considered as a future area of research in the field to better understand related phenomena [12, 13]. The research question addressed in this article is: How do enterprise software providers successively create a technological reference, diffuse it and adapt their strategy to the client's reception? To provide a better understanding to this question, we analyze the shift in SAP's strategy 2025 - According to the German firm, all clients had to migrate from the existing version or the ERP (R/3, mySAP, etc. ) to the latest version: SAP S/4 HANA - based on the analysis of its organizational discourse over eight years (2010-2018). This historical analysis results from the collection of 9 SAP's annual reports and is complemented by independent blogs on IT and Enterprise Systems (ES).

While the evolutionary paradigm shows that lock-in strategies inherently come from the physical attributes of technologies [2], our paper seeks to nuance this result by looking rather at the evolution of the organizational discourse as a trigger to market disruption and to lockin strategies.

\section{ERP systems: From MRP to cloud-based applications}

The aim of the ERP is to integrate the data used throughout the entire organization [11] in order to have all the data of all functions in a unique logical database. The evolution of ERP systems can be summarized in four main periods: closed MRP/ERP systems (1960s1990s); extended ERP systems enablers of interorganizational dynamics (1990s-2000s); ERP as application services providers (2000s-2010s); ERP as cloud-based applications (since 2010s).

\subsection{The origins: from MRP to extended ERP systems (1960s-1990s)}

The roots of ERP systems are found in the 1960s when American large corporations developed centralized computing systems to automate their inventory control systems. While the 1970s witnessed the expansion of material requirements planning (MRP) systems, the 1980s Manufacturing resources planning (MRPII) were developed to extend their scope to other activities such as distribution; finance; human resources and project management. One has to wait until the late 1980s to see the emergence of modern ERP systems, designed as integrators of business processes able to provide increased accessibility and unity across the organization [26].
During the 1990s and the acceleration of ecommerce, the enterprise software industry added modularity to enterprise systems with "extended ERP systems", enablers of inter-organizational dynamics [27]. This extension has been made possible thanks to the modularity of ERP systems. ERP systems, by design are multi-platform and multi-database. The architecture of ERP allowed firm to choose the most suitable operating system environment (i.e. Unix, Microsoft Windows, Linux) as well as the data storage environment as they can operate on multiple relational database such as Oracle, IBM DB2, Microsoft SQL server etc. This flexibility allows firms to integrate the data of the daily operations managed within the boundaries of the ERP systems with the data produced by the best of breed solutions focused on specific processes (such as CRM systems, SCM systems, Transportation systems etc).

\subsection{Recent developments: Application services providers and Cloud-based applications (2000s)}

The rise of ERP systems has provided firms the choice between developing internally software solution to manage business processes and buying packaged software solutions by external vendors. Over time, the choice of buying packaged systems (ERPs) became the only option. However, the internal IT departments kept developing ad-hoc solutions to integrate standard ERP modules or customizing specific functionalities of the installed ERP System. In the early 2000 then, the availability of internet connection, along with its reliability and affordability, allowed software vendors and firms to develop new forms of governance of their ERP systems: ASP (application services provider).

The last decade had seen a significant change ERP system with the integration of cloud-based applications and new solutions for data storage and management. New challenges arise in terms of ease of migration, enhanced by a reliable path between the cloud, the enterprise data center and eventually, between different clouds. It is now often argued that in the long-run, ERP vendors that push their clients to conform exclusively to their standard will find it increasingly challenging to capture existing customers and to find new ones [3], as those strive to mitigate their risks including lock-in effects [6].

The move to cloud is not a mere technical choice. Moving from on-premise software to cloud services affects all business model components [4], as well as way organization manage their process [5]. On top of that, the cloud architecture transfers the control from the client domain to the ERP vendor [30] to a lesser or greater extent depending on the type of cloud options [6]. SAP's 2025 strategy can be interpreted as a platform strategy [24] also involves a new role of SAP in the ERP 
market as it moves from a traditional software provider to a technological change advisor. Aiming at developing a platform-based dynamics, SAP recently tended to adopt a more integrative and participative approach in its relationship with clients and partners.

In the last five years then, data-driven strategies accelerated by the development of Internet of Things and AI have amplified firms' desire of freedom to choose multiple deployment options: from on-premise solutions to multiple clouds. Yet, in this context of integration complexity, enterprise software vendors, that are moving to solutions on cloud, still have a vested interest in making their services sticky and proprietary, potentially leading to lock-in effects for their clients.

As a result, business software providers tend to shift their established traditional strategies towards the development of hybrid technological platforms enhancing more open and flexible solutions. According to research by Gartner [35], by 2022, at least $65 \%$ of large organizations will have implemented a hybrid integration platform. These platforms ambition to lower integration costs, with the help of API (Application Software Interface) management platforms, that partially resolve interdependencies issues between multiple clouds and on-premise platforms. Consequently, the modernization of integration processes is becoming a key element of future IS strategies and drives business systems vendors to adapt significantly. These new challenges have been identified as relevant part of the IS research agenda [17].

\subsection{Cloud options: from IaaS to PaaS to SaaS.}

Cloud Computing refers to the applications, the hardware and software delivered as services over the Internet [12]. However, the more clients rely on vendor's service the more they are locked in [23]. This effect seems to be one of the major justifications for the resistance to the migration to cloud [23]. However, not all cloud models imply the same level of dependency form the vendor. There are in fact three models of cloud services: Infrastructure as a Service (IaaS), Platform as a Service (PaaS), and Software as a Service (SaaS), that target different internal stakeholders of the client firm and bring an increasing level of dependency client vendor [29].

Software as a Service (SaaS), targets the end user or business. It concerns the delivery of a software application over the internet to multiple users. This model where infrastructure and software are vertically integrated by the vendor implies the higher level of lockin [6].

Platform as a Service (PaaS) is the delivery of middleware which contains tools, services and platforms targeting software developers, to allow them to build SaaS application. This model implies some choices, like the development environment and the programming standards that might limit the future degree of freedom of the firm.

Infrastructure as a Service (IaaS) is the delivery of computing power for hardware and software targeted towards administrators. The enterprise pays as it needs and upgrades its usage according to the growth of its business [12]. The ERP vendor can be distinct from the cloud provider. However, in contrast to SaaS mode, the ERP vendor is not responsible for security and has less control [6].

\section{Methodology}

To address our research question, we analyze the organizational discourse of SAP as an emblematic case study, using a qualitative historical analysis complemented by content analysis.

\subsection{Case-study \\ 3.1.1. SAP AG}

With a market of 437.000 clients in 180 countries and 24 billion Euros revenues, SAP is the global leader in the enterprise systems' market [20]. SAP has always been up to its time in the evolution of ERP systems and its philosophy. In the 1980 s, SAP R/ 2 was the MRP that presented some of the architectural concept of the future SAP products. In the early $90 \mathrm{~s}, \mathrm{SAP} R / 3$ was the ERP solution of the German vendor. In the early 2000s, mySAP represented the switch from the traditional ERP to the extended ERP and then SAP Business ByDesign was the ASP offered by SAP. Finally, in 2009, S/4 HANA was introduced as the core of the SAP's cloud strategy. The following figure summarizes this evolution.

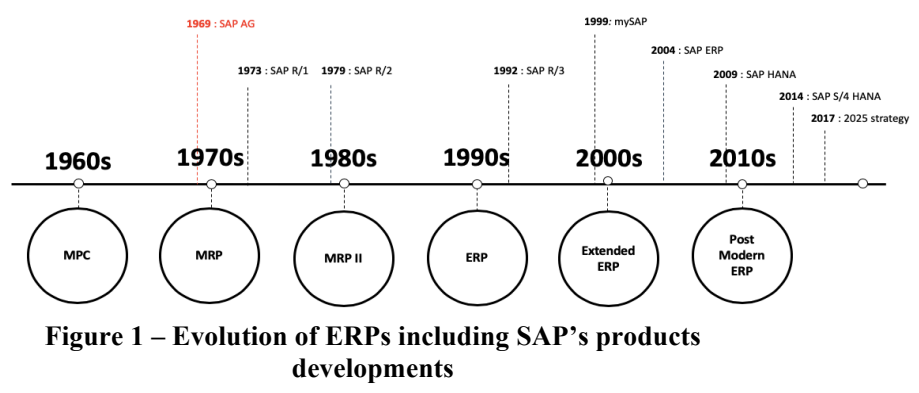

\subsubsection{SAP 2020 / 2025 strategy}

With HANA, SAP entered the Database industry starting a market competition with the traditional partners such as IBM (DB2) and Oracle. In 2009, SAP presented its first Database: HANA (the first product being shipped in November 2010). HANA is a Database designed under a new technological paradigm. First, HANA relies on in-memory technology, i.e. it works on 
the RAM instead of the physical memory devices (hard disks). Second, its architecture - so called columnar represents a discontinuity with the traditional relational databases and provides a significant increase of performance both in the processing and inquiring of data ${ }^{1}$.

In 2014, SAP announced its 5-year strategy called Strategy 2020 (which became Strategy 2025 in 2017).

This new strategy has two main goals:

- migrate all clients from the existing version or the $\operatorname{ERP}(\mathrm{R} / 3$, mySAP, etc.) to the latest version: SAP S/4 HANA on a proprietary platform. In fact, $S / 4$, differently from previous SAP's ERP solutions, can operate only with one database: HANA. However, the system will remain open to third parties' solution though APIs.

- with the tight integration between the application layer and the data layer, SAP is pressuring its clients to move from an "on premise" architecture of their ERP infrastructure to a cloud one. S/4 HANA appears as the core technological hammer for the Cloud strategy of SAP. In the SAP's discourse, HANA is related to topic such as Big Data, Artificial intelligence (AI), Internet of things (IoT), that are not at the centre of the functionalities of the ERP system but that are managed by external solution available separately in SAP product portfolio as App.

SAP's shift towards the development of PaaS and IaaS exemplifies its strategy to develop a digital platform [28], seen as the "extensible codebase of a software-based system that provides core functionality shared by the modules that interoperate with it and the interfaces through which they interoperate" [47, p. 676]." Based on the idea of open platform architecture resulting from two-sided network effects [25], the SAP HANA extension framework of SAP HANA Cloud Platform offers additional options such as the integration of open-source solutions.

Initially called SAP HANA Platform in 2012, it has been renamed SAP Cloud Platform in 2017. It offers customers and partners a possibility to integrate their applications with the platform and by doing that benefit from its capabilities. Any deployment option can be integrated with the platform: on-premises, public cloud, and private cloud. Allowing clients to have a more customizable system, users can now integrate other Cloud-based systems such as SAP ARIBA or SAP SuccessFactors, but also individual applications (SAP or Non-SAP).

\subsection{Historical and content analysis}

\footnotetext{
${ }^{1}$ When HANA was launched, it came with 1TB of RAM, able to support up to 5TB of uncompressed data. In 2011, HANA had 8TB of RAM with support up to 40TB of uncompressed data. In terms of
}

\subsubsection{Historical methods to capture technological change}

Capturing the evolution of SAP strategy - as enterprise software industry changed and new technologies emerged - requires using historical methods, as being temporally contextualized explanations of technological change. This methodological choice echoes the urgent need to develop further long-time horizon analyses to provide a better understanding of platform dynamics [28]. Historical methods are therefore seen as supporting longitudinal studies of technological and organizational change. To capture technological change, scholars in economics and management have used historical methods in two different ways.

First, evolutionary approaches recently used history to document connections between the evolution of technologies and the dynamics of industries' structures [21]. This stream of research assumes that there is a too large gap between complex and messy historical phenomena, on the one hand, and simple and abstract economic theories used to explain and predict them, on the other. As a result, these authors build their theoretical apparatus on "history-friendly (agent-based) models". These general models result from a historical reconstruction of the main characteristics of an industry and on the identification of key factors that might explain the observed patterns [21].

The second use of historical methods to capture technological change is more narrative and interpretive and contrasts with the "experimental-science inspired" aspirations of the first approach. This approach is based on the collection and interpretation of longitudinal data, historical settings and archival sources. This type of historical research views "actors and actions as temporally situated" and emphasizes the "relevance of sequence and context" [7].

Our research question is concerned with the analysis of a longitudinal process, namely the evolution of an enterprise software industry strategy. Consistently, we have chosen a more narrative method based on the evolution of the official discourse of SAP, as an emblematic figure of this industry.

\subsubsection{Content analysis of organizational discourse to capture technological change}

The study of the evolution of SAP strategy lies in the collection of traces of the past left by SAP. This approach emphasizes the constructed and enacted nature of technological change. In our research, the collection of traces of the past was particularly challenging

performances, according to SAP, HANA provides an increase of speed by 1000 time compared traditional Relational Databases. 
because of the absence of any SAP archival company documents such as minutes of the meetings, internal reports, etc [20]. Scholars studied annual reports as a form of language used in the business context and subject to restricted kinds of meanings. In particular, the analysis of thematic structure is of interest in the interpretation of frequency of occurrences. SAP's organizational discourse is here studied with the help of computer-assisted content analysis techniques [18]. Since the early 2000s, this approach became increasingly representative of the rising interest in critical theory in organization studies [13] and information systems research [10].

In line with these lexical techniques, our method consists of identifying keywords before and during data analysis. These keywords are derived from the literature review preliminary conducted and from interest of the researchers. While the general meaning of the text is explored in the context of the technological situation; a quantitative analysis in which counts of relevant keywords to each argument are generated supplements it. Hence, as stated elsewhere: "The number of times an argument or term appears does not provide insight into the meaning of the texts, but it does provide some indication of the themes that dominate the discourse as well as the omissions that may suppress understanding" [10, p. 182]. The main objective is to deal with a large number of data (here: 2418 pages of annual reports) and to highlight semantic constants and relevant occurrences.

Our analysis is supported by $\mathrm{TXM}^{2}$ (modular opensource textometry software) for its coding dimension and by Iramuteq ${ }^{3}$ (interface based on R) concerning the statistical analysis.

On the basis of the results of the emergences of the analysis of the annual report we tried to identify the reaction of the main stakeholder. We analyzed 45 press article and 21 blogs coding their content [16]

\subsection{Data collection and preliminary results 3.3.1. SAP's annual reports (2010-2019)}

As in other companies, SAP's annual reports involve narratives, figures and visuals to convince the readers, namely: investors and shareholders (mostly concerned by the financial part of the report as well as the prospective analysis), clients and prospects (more interested by the products portfolio and the technological trends), business partners (suppliers; consultants; and other intermediaries who are more concerned with the management and the news about
SAP's business ecosystem) and market analysts in general who see annual reports as a signal.

Over the years, SAP's annual reports tend to follow a homogenous structure including the following items ${ }^{4}$ :

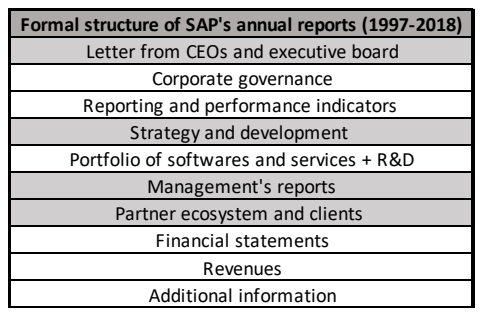

Table 1 - Formal structure of SAP's annual reports over time

In line with our research question, four main "sections" in the report are of particular interest: Letter from CEOs and executive board (read first and symbolizing the direct strategic line of SAP); strategy and development; management's report and partner ecosystem and clients. Overall, annual reports are meant to provide simple, clear and readable information that is understandable by its shareholders [34]. The analysis of these reports is a way to understand how SAP constructs meanings and diffuse them to influence shareholders and clients about a new technological and strategic direction.

Following a macro-level analysis of organizational discourse, our aim here is to discern the trends. In line with our research question, our initial data collection covered the period 1997-2018 and, successively got restricted to the period 2010-2018, since the word "cloud" is used for the first time ( 9 occurrences) in the 2009 report and the word "Hana" is first used in 2010. The 660 occurrences of the term "cloud" in 2018 shows the stabilization of the solution on the enterprise software market.

This preliminary analysis allowed us to justify "time boundaries validity" that addresses the "beginning and ending points of the total observation window" and that aim at capturing "all significant events or effects that occurred in the process under study" [31].

\footnotetext{
${ }^{4}$ In terms of content, all reports share approximately the same formal structures: text segments (between 3000 and 3500 per report); total number of occurrences of different forms (130000-135000) and Hapax (words that only appear once in the corpus: $30-33 \%$ ).
}

\footnotetext{
${ }^{2} \mathrm{http}: / /$ textometrie.ens-lyon.fr

3 http://iramuteq.org
} 


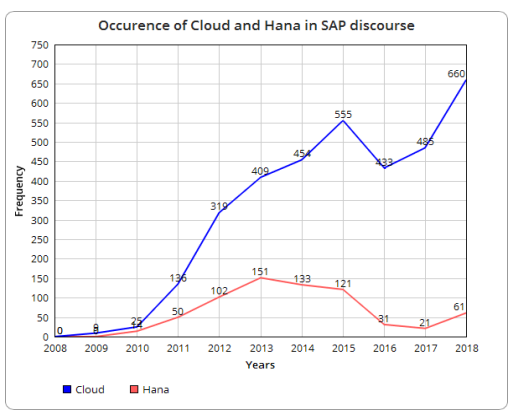

Figure 2 - Occurrences of the term "clouds" and "HANA" in SAP's annual reports (2008-2018)

\subsubsection{Evolution of SAP's organizational discourse} (2010-2019)

Our data shows four main strategic periods emerging from content analysis of SAP's annual reports (see Table 2 for further details):

- 1 - The creation of the reference: 2009-2012 - The emergence of HANA as a superior technology: This first period sees the emergence of HANA and reveals the marketing of the solution as a superior technology on the enterprise software industry. As shown in the following extract, the emphasis is put on its revolutionary nature, concerned with its technological abilities to perform real-time analytics:

"With SAP HANA, organizations can instantly analyze their business operations, using huge volumes of detailed transactional and analytic information from virtually any data source. In addition to revolutionizing customers' access to data, SAP HANA provides the foundation for building new, innovative applications. These applications will leverage the in-memory database and calculation engine within SAP HANA, allowing customers to conduct complex planning, forecasting and simulation based on real-time data." (2010, p. 77)

In the 2011 annual report, the emphasis is put on the computer speed of HANA to process large amount of data in real-time.

"It often increases computing speeds by a factor of 1,000 or more, allowing our customers to work with massive amounts of data in real time. SAP HANA will transform the market and allow us to renew our entire portfolio. It represents the future of $S A P$ and we will continue to coinnovate with partners and customers to realize its full potential. SAP HANA generated revenue of more than $€ 160$ million for the year - making it the fastest growing product in our history." (2011, p. 16)

- 2 - The convergence to the reference: 20122015 - The centrality of HANA as SAP's core product:

\footnotetext{
${ }^{5}$ Under the qualified retail model, the cloud company expects developers to acquire permission and get certified before releasing any new application on its products.
}

As put by its CEO in the 2013 report (p. 21), "SAP HANA is the most successful product in SAP's history. This technology is the basis of all SAP applications in the future". As HANA explicitly becomes the core product of the company, SAP identifies the first risks of failure of this technological strategy.

"Our technology strategy might not succeed, or customers might not adopt our technology platform offering if we are unable to keep up with technological innovations or successfully compete in the market." (2012, p. 140)

Interestingly, the identified risk factors are not concerned with the technological properties of HANA but rather with the development of SAP's ecosystem according to a qualified retail model [19] $]^{5}$. The emphasis is put on the central role that ISV partners have to play in the ecosystem; especially in terms of guidance of current and future customers in their technological choices. This is exemplified in the 2012 annual report that argues:

"we enable and encourage ISV partners to leverage SAP technology by providing guidance about business opportunities, architecture, and technology as well as a comprehensive certification program designed to ensure that third-party solutions are of consistently high quality." (2012, p. 140)

- 3 - The diffusion of the reference: 2015-2017 - The delivery of S/4HANA as SAP's new digital heart: The ease of migration and the customer's experience ("co-engineering" and "co-innovation") starts emerging more significantly in SAP's discourse. As put in the 2015 annual report:

"we work with large enterprise customers to forge a coengineering and co-innovation relationship, so that they can influence and shape existing SAP solutions while gaining early access to product innovation. We help define future software solution standards together with our customers in comprehensive engagements and serve as a trusted advisor during delivery of innovative solutions for the future." $(2015$, p. 34)

These customers still not have explicit freedom of choice except in the flexibility of choosing a specific business model approach. As mentioned in the 2015 annual report, new methods (such as SAP Activate) are introduced to accelerate clients' implementation which was earlier identified as a central strategic risk.

"In mid-2015, we also introduced SAP Activate, an innovation adoption framework to further support the fast and effective implementation of SAP S/4HANA. [...] the new methodology provides ready-to-run digitized business processes optimized for SAP S/4HANA. It allows customers to flexibly choose the approach for their business needs, 
from a new implementation to an integration to a migration scenario." (2015, p. 34)

- 4 - The final stage: 2017-onwards - The increasing freedom offered to customers: In this period, the term HANA is significantly less used than in the earlier ones. The ability of S/4 to only work with HANA leads to the fact that specific type of cloud from different providers is now offered to SAP's customers. New partnerships (Alibaba, Amazon, Google and Microsoft) appear as changes in SAP's strategy and the very own nature of its ecosystem. This is explicitly stated in the 2018 annual report:

"With SAP Cloud Platform, customers are free to choose from a range of infrastructure-as-a-service (IaaS) providers, and today many enterprise customers are choosing more than one provider. SAP has partnered with Alibaba, Amazon, Google, and Microsoft, so our customers can run their applications in an SAP or a third-party data center, or in a combination thereof. We also offer SAP Cloud Platform as a private cloud deployment." (2018, p. 67)

Interestingly, while comparing the use of the three terms "Software-as-a-service - SaaS"; "Platform-as-aservice PaaS" and "Infrastructure-as-a-service - IaaS" we observe that, before 2013, consistently with the belief that HANA was superior, when referring to cloud offerings the organizational discourse mainly insisted with the SaaS mode and did not refer to IaaS mode. Possibly, SAP did not wish to give much freedom and responsibility to its clients by allowing them to codesign the system. After 2013, the three possibilities tend to be communicated equally and more forcefully with a slight edge of SaaS over Paas and of PaaS over IaaS. This hierarchy is consistent over the four phases with the capabilities of client firms for designing but also for mitigating corresponding risks $[27,31]$. The evolution of SAP's strategy also reflects changes in the very own nature of its ecosystem dynamics. As the analysis of reports shows (cf. third column in Table 2), SAP's platform faces an increasing degree of openness as regards its clients first (since 2015) and to other IaaS and PaaS providers (since 2017).

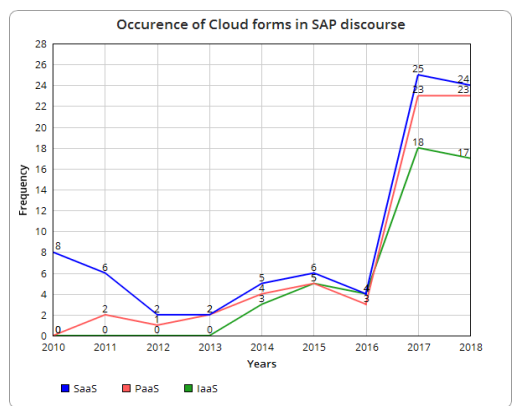

Figure 3 - Occurrences of the terms "SaaS"; "PaaS" and "IaaS" in SAP's annual reports (2010-2018)
As a result, the occurrence of the different forms of cloud offerings in SAP discourse over time could be discussed in relation with the digital ecosystems' dynamics. Consequently, while SAP increasingly develops its activities within a multi-sided market, it leads the company to adapt its solutions and to make them more compatible with other ISV's solutions. In turn, it has been shown elsewhere that it could be profitable for ISV to join the digital platform (especially when it has a well-protected product and developed downstream capabilities) [33].

Due to the magnitude of impact of SAP strategy on partners and clients' strategies, we can observe several critical comments on HANA's performances or $\mathrm{S} / 4$ openness to third parties or the rigidity of cloud offer. As shown in table 2, SAP reacts to these criticisms smoothing the initial statements and highlighting the "positive" impact of its proposal on the ecosystems.

\section{Discussion}

Our data analysis shows how in the last ten years a major software vendor has shaped its strategy to the development of a cloud-based software platform. Our contributions could be assessed at a methodological level and at a more theoretical level.

From a methodological perspective first, the use of a qualitative historical analysis complemented by content analysis allowed us to add "time unit validity" to the understanding of enterprise software providers' strategy. Put differently, we contributed to the IS tradition of longitudinal case studies in the exploration of theoretical ideas concerned with the pace of change of the enterprise systems industry. Since the construct of our time frame results from the data collected in the annual reports, we ensure both "given time unity" and "time boundaries validity" [31]. Based on the belief that meanings are enacted in situated practices and interactively construct social interactions, our results are in line with the position of constitutive causality, seen as one conception for IS theorizing [22].

At a more theoretical level, the identification of four periods of strategic adaptations in SAP's development contributed to the understanding of lockin strategies in the enterprise software industry. Our results show that SAP never sought to give that much freedom to client firms, given their capabilities for designing but also for mitigating corresponding risks [6]. Put differently, this research offers a complementary approach to the analysis of lock-in phenomena that are not only concerned with the material dimension of the technological solution but 
also with the structure of the firm's ecosystem and ISV partners.

The analysis of SAP official discourse shows also that that the implementation of the strategy did not proceed always smoothly. The launch of HANA, as technological supremacy, was in line with the traditional strategy and communication style of the company. When the discourse revealed the strategic role of the technology (HANA), as core of the new SAP's architecture (also called $\mathrm{S} / 4$ platform), the discourse started including organizational and interorganizational relationships with the key partners and their role in the success of the new technology in order to avoid or at least, to mitigate the rejection of the new architecture by the partners base.

The third phase had the clients at the center of the communication. The persuasion went through the emphasis of the easiness of the migration and the offer of competitive prices for the licenses of the new architecture based on HANA.

Finally, there was the discourse on the cloud and its execution. In the discourse we can notice a slight but steady adjustment of the cloud strategy. From a dominance of the SaaS offer on SAP datacenters, where SAP could exercise the higher level of control over the administration of technological environment, to a emergence of the alternative options, such as PaaS and IaaS, and the agreement with third parties such as Ariba, became relevant in the communication strategy of the company in order to mitigate the perception of the possible lock-in effect [44]. Eventually, the evolution of the discourse to the Cloud, and its adaptation over time seems also to be influenced by the reaction to SAP announcements by the press and independent bloggers (cf. table 2).

\section{Limits and further research}

Results discussed in this paper are a first step towards further research concerned with lock-in issues in the business cloud-based platform software industry. Further avenues of research could complement these first results.

First, the analysis of SAP's organizational discourse based on content analysis could be significantly enriched by a systematic analysis of SAP's customers group. Some commentators argue that these groups could form some pressure on software providers, by listing their own preferences and "use them to serve notice to the vendors". To them:

"If this mobility [between clouds] is granted sooner rather than later, the immense potential of cloud computing can be realized sooner as well, and I doubt that competent vendors would be injured by such a development. User groups often produce spokespersons who are skilled at producing such a message." [9, p. 119]. This complementary research could help our understanding of interactions between clients' reactions and providers' adapted strategy. Further research material could also include interviews with current or potential SAP's clients and questionnaires sent to different categories of users.

Second, our research based on a single case-study longitudinal analysis could be strengthened by a comparative analysis at the market level. In the same vein of our study of the SAP case, the understanding of Oracle and Sage's strategy in the same period could be of particular interest in a more market-level discussion of lock-in strategies.

\section{References}

[1] Y. Amanatullah, C. Lim, H.P. Ipung, and A. Juliandri, "Toward Cloud Computing Reference Architecture: Cloud Service Management Perspective". International Conference on ICT for Smart Society, 2013: p. 1-4.

[2] W. B. Arthur, "Competing Technologies, Increasing Returns, and Lock-In By Historical Events", The Economic Journal, 1989. (99): p. 116-131.

[3] C. Babcock, "Management Strategies for the Cloud Revolution - How Cloud Computing Is Transforming Business and Why You Can't Afford to Be Left Behind", 2010. Mc Graw Hill.

[4] T. Boillat and C. Legner, "From On-Premise Software to Cloud Services: The Impact of Cloud Computing on Enterprise Software Vendors' Business Models". Journal of theoretical and applied electronic commerce research, 2013. 8(3): p. $39-58$.

[5] T. Boillat, and C. Legner, "Why Do Companies Migrate Towards Cloud Enterprise Systems? A Post-Implementation Perspective". IEEE 16th conference on business informatics, 2014. (1): p. 102-109.

[6] N. Brender and I. Markov, "Risk Perception and Risk Management in Cloud Computing: Results from a Case Study of Swiss Companies", International Journal of Information Management, 2013. 33(5): p. 726-733.

[7] M. Bucheli and R. D. Wadhwani (Eds.), "Organizations in Time - History, Theory, Methods”, Oxford University Press, 2014.

[8] P. Constantinides, O. Henfridsson, G. G. Parker, "Introduction-Platforms and Infrastructures in the Digital Age". Information Systems Research. 2018. 29(2): p. 381-400

[9] J. W. Cortada, "The Digital Hand - How Computers Changed the Work of American Manufacturing, Transportation and Retail Industries", Oxford University Press, 2004. 
[10] W. Cukier, O. Ngwenyama, R. Bauer and C. Middleton, "A Critical Analysis of Media Discourse on Information Technology: Preliminary Results of a Proposed Method for Critical Discourse Analysis", Information Systems Journal, 2009. (19): p. 175-196.

[11] T. H. Davenport, "Putting the Enterprise in the Enterprise System". Harvard Business Review, 1998. 76(4): p. 121-131.

[12] J. Duan, P. Faker, A. Fesak, and T. Stuart, "Benefits and Drawbacks of Cloud-Based Versus Traditional ERP Systems". Proceedings of the 2012-13 course on Advanced Resource Planning. 2013.

[13] Fairclough N., "Discourse Analysis in Organization Studies: The Case for Critical Realism", Organization Studies, 2005. 26(6): p. 915-939.

[14] L. Gao and A. G. Brink, "A Content Analysis of the Privacy Policies of Cloud Computing Services". Journal of Information Systems. 2018. In Press.

[15] A. Gawer, "Bridging Differing Perspectives on Technological Platforms: Toward an Integrative Framework", Research Policy, 2014. 43(7). pp. 1239-1249.

[16] B. G. Glaser, "The Constant Comparative Method of Qualitative Analysis", Social Problems. 12(4): 436-445.

[17] S. V. Grabski, S.A. Leech, and P. J. Schmidt, "A Review of ERP Research: A Future Agenda for Accounting Information Systems", Journal of Information Systems, 2011. 25(1): p. 37-78.

[18] H.F. Hsieh and S.E. Shannon, "Three Approaches to Qualitative Content Analysis", Qualitative Health Research, 2005. 15(9): p. 1277-1288.

[19] B. Iyer and J.C. Henderson, "Business Value of Clouds: Learning from Users", MIS Quarterly Executive, 2012. 11(1): p. $1-10$.

[20] T. Leimbach, "The SAP Story: Evolution of SAP Within the German Software Industry", IEEE Annals of the History of Computing, 2008: p. 60-76.

[21] F. Malerba, R.R. Nelson, L. Orsenigo and S.G. Winter, "Innovation and the Evolution of Industries - History-friendly Models", Cambridge University Press, 2016.

[22] M. L. Markus and F. Rowe, "Is IT Changing the World? Conceptions of Causality for Information Systems Theorizing”, MIS Quarterly, 2018. 42(4): p. 1255-1280.

[23] J. Opara-Martins, R. Sahandi, \& F. Tian, "Critical Review of Vendor Lock-In and its Impact on Adoption of Cloud Computing". 2014. International Conference on Information Society (i-Society 2014), IEEE: p. 92-97.
[24] G.G. Parker, M.W. Van Alstyne, \& S.P. Choudary, "Platform Revolution: How Networked Markets Are Transforming the Economy and How to Make Them Work for You”. WW Norton \& Company. 2016.

[25] G. Parker \& M. Van Alstyne, "Two-Sided Network Effects: A Theory of Information Product Design". Management Science. 2005. 51(10): p. 1494-1504.

[26] G.C. Peng and C.J. Gala, "Cloud ERP: A New Dilemma to Modern Organisations?" Journal of Computer Information Systems. 2014. 54 (4): p. 22-30.

[27] M.A. Rashid, L. Hossain, and J.D. Patrick, "The Evolution of ERP Systems: A Historical Perspective, In: Enterprise Resource Planning: Global Opportunities, Challenges and Solution", Hossain, L., Patrick, J., and Rashid, M. A (Edited), Idea Group Publishing, USA, 2002: p. 1-16.

[28] M. de Reuver, C. Sørensen, and R.C. Basole, "The Digital Platform: A Research Agenda". Journal of Information Technology. 2018. 33(2): p. 124-135.

[29] F. Scavo, J. Longwell, B. Newton, "Choosing Between Cloud and Hosted ERP, and Why It Matters". Computer Economics Report. 2012. 34(8): p. 1.

[30] M. Schreieck, M. Wiesche, T. Kude, and H. Kremar, "Shifting to the Cloud - How SAP's Partners Cope with the Change", Proceedings of the $52^{\text {nd }}$ Hawaii International Conference on System Sciences, 2019: p. 6084-6093.

[31] C. T. Street and K. W. Ward, "Improving Validity and Reliability in Longitudinal Case Study Timelines", European Journal of Information Systems, 2012. 21(2): p. 160-175.

[32] D. Teece, "Profiting from Innovation in the Digital Economy: Enabling Technologies, Standards, and Licensing Models in the Wireless World", Research Policy, 2018. 47(8): p. 1367-1552.

[33] A. Tiwana, B. Konsynski \& A.A. Bush, "Platform Evolution: Coevolution of Platform Architecture, Governance, and Environmental Dynamics". Information Systems Research. 2010. 21(4): p. 675-687.

[34] J. Thomas, "Discourse in the Marketplace: The Making of Meaning in Annual Reports", The Journal of Business Communication, 1997. 34(1): p. 47-66.

[35] R. Van der Meulen, "Use a Hybrid Integration Approach to Empower Digital Transformation", Gartner's report. 26 April 2018.

This work has been supported by the French government, through the UCA JEDI and EUR DS4H Investments in the Future projects managed by the National Research Agency $(A N R)$ with the reference number ANR15-IDEX-0001 and ANR-17-EURE-0004. 


\begin{tabular}{|c|c|c|c|}
\hline Strategic periods & $\begin{array}{l}\text { Strategic choices identified in } \\
\text { SAP's discourse }\end{array}$ & Understanding of SAP's strategy (blogs and press) & $\begin{array}{c}\text { Theoritical insights in terms of } \\
\text { platform's architecture evolution and } \\
\text { ecosystem's dynamics }\end{array}$ \\
\hline \multirow[b]{2}{*}{$\begin{array}{l}2009-2012- \\
\text { Creation of the } \\
\text { reference }\end{array}$} & \multirow[b]{2}{*}{$\begin{array}{l}\text { HANA marketed as a superior } \\
\text { "revolutionary" technology (real- } \\
\text { time analytics of huge-volume } \\
\text { data) on the business software } \\
\text { market - no specific mention to } \\
\text { the specificity of SAP's ecosystem }\end{array}$} & $\begin{array}{c}\text { plan to have } 200.000 \text { clients on HANA in } 10 \text { years doubts, controversial view... - } \\
\text { SAP's 10-year HANA gamble: A life without the big boys } \\
\text { (https://www.theregister.co.uk/2015/02/18/sap_10_year_hana_gamble_so_long } \\
\text { _ibm_oracle_microsoft/) }\end{array}$ & \multirow[b]{2}{*}{$\begin{array}{l}\text { Other ecosystem's actors (such as } \\
\text { competitors, partners, vendors, etc...) } \\
\text { are mostly absent. }\end{array}$} \\
\hline & & $\begin{array}{c}\text { "HANA is the foundation and the core of all that we do now and going forward for } \\
\text { existing products, new products and entirely new frontiers. We are transforming } \\
\text { enterprise software with HANA, and we are transforming our entire product } \\
\text { portfolio," Sikka said in a statement earlier this week announcing that SAP HANA is } \\
\text { now generally available worldwide. (The Top } 10 \text { Reasons SAP HANA Is Disrupting } \\
\text { Larry Ellison's Grand Plans Bob Evans Forbes } 2011 \\
\text { https://www.forbes.com/sites/sap/2011/06/23/the-top-10-reasons-sap-hana-is- } \\
\text { disrupting-larry-ellisons-grand-plans/\#45bc2bb23e92) }\end{array}$ & \\
\hline $\begin{array}{l}2012-2015- \\
\text { Convergence to the } \\
\text { reference }\end{array}$ & $\begin{array}{l}\text { As a result of the identification of } \\
\text { the first risks in terms of the } \\
\text { ecosystem development; SAP uses } \\
\text { an "agressive" strategy of } \\
\text { communication. It also } \\
\text { strengthens the quality and the } \\
\text { scope of the ecosystem } \\
\text { (leveraging the technology and } \\
\text { ensure third-party solutions' } \\
\text { quality) }\end{array}$ & $\begin{array}{c}\text { SAP's fastest-selling product of all time, known as HANA, may not be as growing as } \\
\text { fast as the company says, according to one Wall Street analyst. (Julie Bort Business } \\
\text { Insider } 2013 \text { https://www.businessinsider.com/analyst-says-saps-hana-database- } \\
\text { may-not-be-as-successful-as-it-seems-2013-4) }\end{array}$ & $\begin{array}{c}\text { Openness to ISV and increasing role of } \\
\text { the ecosystem }\end{array}$ \\
\hline $\begin{array}{l}2015-2017 \text { - } \\
\text { Diffusion of the } \\
\text { reference }\end{array}$ & $\begin{array}{l}\text { The emphasise is put on } \\
\text { customers' guidance in their } \\
\text { implementation to use S4/HANA } \\
\text { as their new digital core. } \\
\text { Particular focus on the ease of } \\
\text { migration and on co-innovation's } \\
\text { desire }\end{array}$ & $\begin{array}{c}\text { SAP intends to shape HANA as an "all-inclusive data platform" incorporating all } \\
\text { data types and approaches to storage, data processing and delivery in the same } \\
\text { place, Khan says. (ASUG admin Feb 2015/ https://www. asug.com/news/saps-2020- } \\
\text { platform-vision-iot-open-standards-and-partnerships ) }\end{array}$ & $\begin{array}{l}\text { Openness to clients' needs to develop a } \\
\text { more flexible approach }\end{array}$ \\
\hline $\begin{array}{l}\text { 2017-onwards - The } \\
\text { final stage }\end{array}$ & $\begin{array}{l}\text { Explicit risks identified lead to } \\
\text { more freedom addressed to the } \\
\text { final clients; the term "HANA" is } \\
\text { relatively less used in the } \\
\text { communication }\end{array}$ & \begin{tabular}{|} 
Like every tech megavendor competing in the Cloud Wars, SAP has its challenges: \\
- savage competition for SaaS deals from cloud natives Salesforce.com and \\
Workday as well as from longtime nemesis Oracle; \\
a huge product lineup that can at times be difficult to orchestrate elegantly; \\
- a rapidly evolving competitive landscape in the cloud where laaS superpower \\
Amazon along with resurgent IBM and fast-growing Google will inevitably want to \\
expand into the SaaS and PaaS segments where SAP does well; and \\
- a strategic partnership with Microsoft that offers tremendous promise but also \\
potentially distorts the clarity of SAP's own cloud and digital-business aspirations. \\
(Bob Evans - Forbes 2018 - \\
https://www.forbes.com/sites/bobevans1/2018/02/20/inside-sap-as-cloud- \\
surpasses-license-revenue-in-2018-10-strategic-insights/\#39c9371e7207)
\end{tabular} & $\begin{array}{l}\text { Openness to other laaS and PaaS } \\
\text { providers }\end{array}$ \\
\hline
\end{tabular}

